\title{
(6) OPEN ACCESS \\ Usual alcohol consumption and suicide mortality among the Korean elderly in rural communities: Kangwha Cohort Study
}

\author{
Sang-Wook Yi, ${ }^{1,2}$ Myoungjee Jung, ${ }^{3}$ Heejin Kimm, ${ }^{4}$ Jae-Woong Sull, ${ }^{5}$ Eunsook Lee, ${ }^{6}$ \\ Kwang Ok Lee, ${ }^{6}$ Heechoul Ohrr $^{7}$
}

\begin{abstract}
- Additional material is published online only. To view please visit the journal online (http://dx.doi.org/10.1136/jech2015-206849).
\end{abstract}

For numbered affiliations see end of article.

\section{Correspondence to} Professor Sang-Wook Yi, Department of Preventive Medicine and Public Health, Catholic Kwandong University College of Medicine, Gangneung, 24, Beomil-ro 579-beon-gil, Gangneung-si, Gangwon-do 25601, Republic of Korea; flyhigh@cku.ac.kr

SWY and MJ contributed equally to this work as first authors.

Received 21 October 2015 Revised 11 January 2016 Accepted 28 January 2016 Published Online First 17 February 2016

\section{CrossMark}

\author{
To cite: Yi SW, Jung $M$, \\ Kimm H, J Epidemiol \\ Community Health \\ 2016:70:778-783.
}

\section{ABSTRACT}

Background The evidence from prospective studies on whether greater usual alcohol consumption is associated with a higher risk of death by suicide in the general population is inconclusive.

Methods 6163 participants (2635 men; 3528 women) in a 1985 survey among rural residents in Korea aged 55 years and above were followed until 2008. A Cox model was used to calculate HRs of suicide death after adjustment for demographic, socioeconomic and healthrelated confounders.

Results 37 men and 24 women died by suicide. Elderly persons who consumed alcohol daily, $70 \mathrm{~g}$ alcohol (5 drinks) or more per drinking day, or $210 \mathrm{~g}$ alcohol (15 drinks) or more per week had higher suicide mortality $(p<0.05)$, compared with non-drinkers. An increase of one drinking day per week $(H R=1.17,95 \%$ $\mathrm{Cl} 1.05$ to 1.31$), 70 \mathrm{~g}$ (5 drinks) additional alcohol intake per drinking day $(\mathrm{HR}=1.38,95 \% \mathrm{Cl} 1.13$ to 1.70), and $140 \mathrm{~g}$ (10 drinks) additional alcohol intake per week was associated with a $17 \%, 38 \%$ and $12 \%$ higher risk of suicide death, respectively. Women had a higher relative risk of suicide death associated with alcohol consumption, compared with men.

Conclusions A greater frequency and amount of usual alcohol consumption was linearly associated with higher suicide death. Given the same amount of alcohol consumption, women might have a higher relative risk of suicide than men. Our findings support 'the lower the better' for alcohol intake, no protective effect of moderate alcohol consumption, and a sex-specific guideline (lower alcohol threshold for women) as actions to prevent suicide death.

\section{INTRODUCTION}

Death by suicide is a leading cause of death, ${ }^{1}$ and initiatives to advance suicide prevention programmes are a high priority in many countries. ${ }^{2}$ Harmful alcohol use has been recognised as a strong risk factor for suicide death. ${ }^{2}$ In psychological autopsy studies, alcohol use disorder was strongly associated with suicide death $(\mathrm{OR}=5.2$, 95\% CI 3.3 to 8.3$){ }^{3}$ and heavy alcohol use was also strongly linked with suicide death $(\mathrm{OR}=6.2$, $95 \%$ CI 5.6 to 6.9 in men). ${ }^{4}$ In a recent systematic review of the prospective studies, however, the magnitude of the association between alcohol use disorder and suicide death was reported to be moderate (pooled risk ratio $=1.74$, 95\% CI 1.26 to 2.21). The strong associations reported in psychological autopsy studies and case-control studies may have resulted, at least in part, from several biases such as surrogate interview bias and recall bias.

Furthermore, when usual alcohol consumption rather than alcohol use disorder is considered in the general population, evidence of the impact of usual alcohol consumption on suicide death is less than convincing. Results from the majority of prospective studies, including cohort studies and nested case-control studies based on a prospective cohort, have indicated that alcohol consumption was not associated with a higher risk of suicide death, compared to no alcohol consumption, even in the group with the highest consumption in each study, ${ }^{5-11}$ with a few exceptions. ${ }^{12}{ }^{13}$ Overall, the association between usual alcohol consumption and suicide death is unclear. Since the majority of adults drink alcohol at some point in their life, a better understanding of usual alcohol consumption and suicide death should inform decision-making for better suicide prevention strategies in the general population.

The purpose of this study was to prospectively examine the association of usual alcohol intake-related variables including alcohol intake frequency, average alcohol consumption and quantity of alcohol consumed on a drinking day with suicide death in a community dwelling elderly population in Korea. We tried to elucidate questions such as whether greater usual alcohol consumption is associated with a greater risk of suicide death (dose-response relationship), and whether moderate alcohol consumption (below 5 drinks/ week, or 4 or fewer drinking days a month) has a protective effect against suicide death compared to abstaining completely.

\section{METHODS}

\section{Study population}

The Kangwha Cohort Study was established in March 1985. ${ }^{14}{ }^{15}$ Among 9378 residents of Kangwha County in Korea who were 55 years or older as of February 1985, 6372 persons (67.9\%) participated in the survey. Participants who were lost to follow-up after the initial survey $(n=39)$ were excluded, as were those with missing information about drinking status $(n=2)$, their body mass index (BMI; $n=143)$, or other covariates $(n=25)$. In the end, a total of 6163 elderly (2635 men; 3528 women) were included as a study population. The Institutional Review Board of Yonsei University (Approval No. 4-2007-0182) approved the study. 


\section{Estimation of usual alcohol consumption}

Participants were asked to answer 'yes' or 'no' to the question, 'Do you drink alcohol?' The drinking frequency was reported as daily, almost daily, 2-3 times a week, 1-4 times a month or 412 times a year. The question concerning the type of alcoholic beverage and the amount of alcohol consumption was, 'How much (in doe $(1800 \mathrm{~mL})$, hop $(180 \mathrm{~mL})$, bottles or glasses) do you drink of a type of alcoholic beverage?' Alcohol consumption (alcohol in grams) per week was estimated by multiplying the amount of alcohol consumption per drinking day $(\mathrm{mL})$ by the alcohol content in the particular type of alcoholic beverage, the drinking days per week, and the specific gravity of alcohol (0.8). A different score for drinking days per week was assigned to each drinking frequency (daily: 7.0 ; almost daily: $5.5 ; 2-3$ times a week: $2.5 ; 1-4$ times a month: $0.625 ; 4-12$ times a year: 0.163; non-drinking: 0). Participants were asked to fill in up to two types of alcoholic beverage they usually consume on one drinking day. The amount of alcohol consumption was calculated for each type and summed. Among drinkers, 15.2\% reported two types. The alcohol content and the bottle volume of each type of alcoholic beverage were determined on the basis of data from the year 1985. Soju and makkoli were the most commonly consumed alcoholic beverages. Soju is a distilled alcoholic beverage, a type of liquor, and makkoli is an unfiltered alcoholic beverage made from rice, both native to Korea. Soju had 25\% alcohol and makkoli $6 \%$ alcohol at the time of the survey for the Kangwha Cohort Study in 1985. The amount of ethanol was $10 \mathrm{~g}$ in a glass of soju and $9.6 \mathrm{~g}$ in a glass of makkoli.

The alcohol frequency was merged into four groups in further analysis: daily, 2-6 days a week (almost daily and 2-3 times a week combined), 4 or fewer days a month (1-4 times a month and 4-12 times a year combined), and non-drinkers. The alcohol intake amount (grams of alcohol) per week was classified into four groups (grams of alcohol per week (drinks per week, with 1 drink as $14 \mathrm{~g}$ of alcohol ${ }^{16}$; non-drinkers, $<70(<5$ drinks); 70-209 (5-14), 210-419 (15-29), and $\geq 420$ ( $\geq 30)$ ). The amount consumed (grams of alcohol) per drinking day was classified into four groups (grams of alcohol per drinking day (drinks per occasion); non-drinkers, $<70$ ( $<5$ drinks); 70-139 $(5-9)$, and $\geq 140(\geq 10))$. One standard drink was considered to be around $14 \mathrm{~g} .{ }^{16}$ The alcohol intake frequency (number of days) per week, alcohol intake volume per week, and alcohol intake amount per drinking day were also analysed as continuous variables.

\section{Baseline data collection}

Trained investigators interviewed each participant using a structured questionnaire for sociodemographic factors and health-related factors including alcohol intake-related variables, smoking status and marital status. They also measured participants' height, weight and blood pressure. BMI was calculated as the weight in kilograms divided by the square of the height in metres $\left(\mathrm{kg} / \mathrm{m}^{2}\right)$. More details on the data collection have been described elsewhere. ${ }^{14} 15$

\section{Follow-up and outcome assessment}

Data on deaths from suicide from 1 January 1992 to 31 December 2008 were confirmed by national death records from the National Statistical Office of Korea. Data on those who died from March 1985 to 31 December 1991 were collected either through calls or visits of trained surveyors twice a year, or from records of burial and death certificates at local administrative branch offices in each study region. Follow-up was performed through record linkage at the national level and was complete, except for the case of emigrants. A complete follow-up was made for 6151 (99.8\%) participants. Suicide was identified by the International Classification of Diseases, 10th Revision codes X60-X84.

\section{Statistical analysis}

The $\chi^{2}$ test and analysis of variance were performed to compare individual characteristics by drinking status. Cox proportional hazards models were used to calculate HRs associated with alcohol intake-related variables. The covariables included in the Cox model were age at enrolment (continuous variable), hypertension (hypertension, no hypertension; an indicator for cardiovascular health ${ }^{6}$ ), smoking (never smoker, past smoker, or current smoker; participants were asked to answer 'yes', 'no', or 'I quit smoking' to the question, 'Do you smoke cigarettes?'), BMI $\left(\mathrm{kg} / \mathrm{m}^{2} ;<18.5,18.5-24.9\right.$ (reference), or $\left.\geq 25.0\right)$, self-rated health (good or fair, or poor), marital status (living with a spouse, not living with a spouse), education (ever, never) and occupation (non-agriculture, agriculture). Since the number of suicide deaths is small, there is a possibility of overfitting when all those potential confounders are included in the Cox model; thus, additional analysis was performed, including only those variables with the model $\mathrm{p}$ value $<0.2$ for the Wald test in the univariate Cox analysis: sex, smoking status, self-rated health compared to the same age group, marital status and occupation.

Analysis according to sex was performed. Additionally, analysis according to the follow-up period (1985-1996 vs 1997 2008) was performed to examine whether alcohol-related suicide death may differ by period after alcohol intake assessment. The proportional assumption for the Cox model was tested using Schoenfeld and Martingale residuals. Hypertension, marital status and a dummy variable for BMI $\left(\geq 25 \mathrm{~kg} / \mathrm{m}^{2}\right)$ showed some evidence of a violation of the assumption $(p<0.1)$. Therefore, additional analyses after exclusion of these three variables, or exclusion of the hypertension and BMI variables after stratification of marital status (since marital status $(p=0.013)$, was associated with suicide death in univariate Cox analysis, while BMI $(p=0.51)$ and hypertension $(p=0.36)$ were not) were performed. Subgroup analysis, analysis with different alcohol intake variables, and additional analysis with different covariables served as a sensitivity analysis.

All statistical analyses were performed using SAS V.9.4 (SAS Inc, Cary, North Carolina, USA). The $\mathrm{p}$ value was calculated with two-sided tests, and a statistical significance level of 0.05 was applied.

\section{RESULTS}

During 88376 person-years of follow-up (mean: 14.3 personyears), 37 men and 24 women died by suicide. The average (SD) age at baseline of the Korean elderly was $66.6(7.9)$ years. Current drinkers were slightly younger than non-drinkers, and they tended to be men, current smokers, healthy, living with a spouse and have more formal education, compared with non-drinkers (table 1).

In the unadjusted analysis, current drinkers had a higher HR of suicide than non-drinkers and higher frequency and amount of alcohol intake were associated with a higher HR of suicide (table 2). Two or more days of alcohol intake per week, $70 \mathrm{~g}(5$ drinks) or more of alcohol consumption per drinking day, and $210 \mathrm{~g}$ (15 drinks) or more alcohol consumption per week were associated with higher suicide mortality, compared with nondrinkers, in the unadjusted analysis. After adjustment for potential confounders, linear associations between alcohol 
Table 1 Baseline characteristics of the Korean elderly according to alcohol intake status

\begin{tabular}{|c|c|c|c|c|c|}
\hline & & $\begin{array}{l}\text { Total } \\
(\mathrm{N}=6163)\end{array}$ & $\begin{array}{l}\text { Non-drinker } \\
(\mathrm{N}=4082)\end{array}$ & $\begin{array}{l}\text { Drinker } \\
(\mathrm{N}=2081)\end{array}$ & \\
\hline Variable & Classitication & & & & p value ${ }^{*}$ \\
\hline Age at enrolment & Mean (SD), years & $66.6(7.9)$ & $67.1(8.3)$ & $65.8(7.0)$ & $<0.001 \dagger$ \\
\hline Gender & $\begin{array}{l}\text { Women } \\
\text { Men }\end{array}$ & $\begin{array}{l}3528(57.2) \\
2635(42.8)\end{array}$ & $\begin{array}{r}3165(77.5) \\
917(22.5)\end{array}$ & $\begin{array}{r}363(17.4) \\
1718(82.6)\end{array}$ & $<0.001$ \\
\hline Smoking & $\begin{array}{l}\text { Current smoker } \\
\text { Past smoker } \\
\text { Never smoker }\end{array}$ & $\begin{array}{c}2748(44.6) \\
267(4.3) \\
3148(51.1)\end{array}$ & $\begin{array}{c}1182(29.0) \\
144(3.5) \\
2756(67.5)\end{array}$ & $\begin{array}{c}1566(75.3) \\
123(5.9) \\
392(18.8)\end{array}$ & $<0.001$ \\
\hline Body mass index, $\mathrm{kg} / \mathrm{m}^{2}$ & $\begin{array}{l}<18.5 \\
18.5-24.9 \\
\geq 25.0\end{array}$ & $\begin{array}{c}556(9.0) \\
4563(74.0) \\
1044(16.9)\end{array}$ & $\begin{array}{c}377(9.2) \\
2908(71.2) \\
797(19.5)\end{array}$ & $\begin{array}{r}179(8.6) \\
1655(79.5) \\
247(11.9)\end{array}$ & $<0.001$ \\
\hline Hypertension $\ddagger$ & $\begin{array}{l}\text { No } \\
\text { Yes }\end{array}$ & $\begin{array}{l}2505(40.6) \\
3658(59.4)\end{array}$ & $\begin{array}{l}1708(41.8) \\
2374(58.2)\end{array}$ & $\begin{array}{r}797(38.3) \\
1284(61.7)\end{array}$ & 0.007 \\
\hline Self-rated health & $\begin{array}{l}\text { Good or fair } \\
\text { Poor }\end{array}$ & $\begin{array}{l}4692(76.1) \\
1471(23.9)\end{array}$ & $\begin{array}{l}3039(74.4) \\
1043(25.6)\end{array}$ & $\begin{array}{r}1653(79.4) \\
428(20.6)\end{array}$ & $<0.001$ \\
\hline Marital status & $\begin{array}{l}\text { Living with a spouse } \\
\text { Not living with a spouse }\end{array}$ & $\begin{array}{l}4043(65.6) \\
2120(34.4)\end{array}$ & $\begin{array}{l}2357(57.7) \\
1725(42.3)\end{array}$ & $\begin{array}{r}1686(81.0) \\
395(19.0)\end{array}$ & $<0.001$ \\
\hline Education & $\begin{array}{l}\text { Ever } \\
\text { Never§ }\end{array}$ & $\begin{array}{l}2255(36.6) \\
3908(63.4)\end{array}$ & $\begin{array}{l}1167(28.6) \\
2915(71.4)\end{array}$ & $\begin{array}{r}1088(52.3) \\
993(47.7)\end{array}$ & $<0.001$ \\
\hline Occupation & $\begin{array}{l}\text { Non-agriculture } \\
\text { Agriculture }\end{array}$ & $\begin{array}{l}1079(17.5) \\
5084(82.5)\end{array}$ & $\begin{array}{r}737(18.1) \\
3345(81.9)\end{array}$ & $\begin{array}{r}342(16.4) \\
1739(83.6)\end{array}$ & 0.113 \\
\hline Alcohol intake status & $\begin{array}{l}\text { Non-drinker } \\
\text { Drinker }\end{array}$ & $\begin{array}{l}4082(66.2) \\
2081(33.8)\end{array}$ & $\begin{aligned} 4082 & (100.0) \\
0 & (0.0)\end{aligned}$ & $\begin{array}{c}0(0.0) \\
2081(100.0)\end{array}$ & $<0.001$ \\
\hline Alcohol intake frequency & $\begin{array}{l}\text { Non-drinker } \\
4 \text { or fewer days a month } \\
\text { 2-6 days a week } \\
\text { Daily }\end{array}$ & $\begin{aligned} 4082 & (66.2) \\
607 & (9.8) \\
1009 & (16.4) \\
465 & (7.5)\end{aligned}$ & $\begin{array}{c}4082(100.0) \\
0(0.0) \\
0(0.0) \\
0(0.0)\end{array}$ & $\begin{aligned} & 0(0.0) \\
& 607(29.2) \\
& 1009(48.5) \\
& 465(22.3)\end{aligned}$ & $<0.001$ \\
\hline $\begin{array}{l}\text { Alcohol intake amount, } g \text { alcohol/drinking day } \\
\text { (drink/drinking day) }\end{array}$ & $\begin{array}{l}\text { Non-drinker } \\
\text { Below } 70 \mathrm{~g} \text { ( } 5 \text { drinks) } \\
70-139 \mathrm{~g} \text { ( } 5-9 \text { drinks) } \\
140 \mathrm{~g} \text { or over ( } \geq 10 \text { drinks) }\end{array}$ & $\begin{array}{c}4082(66.2) \\
1037(16.8) \\
732(11.9) \\
312(5.1)\end{array}$ & $\begin{array}{c}4082(100.0) \\
0(0.0) \\
0(0.0) \\
0(0.0)\end{array}$ & $\begin{array}{c}0(0.0) \\
1037(49.8) \\
732(35.2) \\
312(15.0)\end{array}$ & $<0.001$ \\
\hline $\begin{array}{l}\text { Alcohol intake amount, g alcohol/week } \\
\text { (drink/week) ๆ }\end{array}$ & $\begin{array}{l}\text { Non-drinker } \\
\text { Below } 70 \mathrm{~g} \text { ( } 5 \text { drinks) } \\
70-209 \mathrm{~g} \text { (5-14 drinks) } \\
210-419 \mathrm{~g} \text { (15-29 drinks) } \\
420 \mathrm{~g} \text { or over ( } \geq 30 \text { drinks) }\end{array}$ & $\begin{array}{l}4082(66.2) \\
729(11.8) \\
449(7.3) \\
328(5.3) \\
575(9.3)\end{array}$ & $\begin{array}{c}4082(100.0) \\
0(0.0) \\
0(0.0) \\
0(0.0) \\
0(0.0)\end{array}$ & $\begin{array}{c}0(0.0) \\
729(35.0) \\
449(21.6) \\
328(15.8) \\
575(27.6)\end{array}$ & $<0.001$ \\
\hline
\end{tabular}

${ }^{*} \chi^{2}$ analysis.

tOne-way analysis of variance.

‡Measured blood pressure $\geq 140 / 90 \mathrm{~mm} \mathrm{Hg}$ or on regular medication.

$\S$ No formal education, not even elementary school.

१1 standard drink considered to be approximately $14 \mathrm{~g}$ according to the National Institute on Alcohol Abuse and Alcoholism of the USA.

BMI, body mass index.

consumption and suicide mortality were maintained. Adjusted HRs of one drinking day increase per week, each $70 \mathrm{~g}$ (5 drinks) higher alcohol intake per drinking day, and each $140 \mathrm{~g}$ (10 drinks) higher alcohol intake per week, were 1.17, 1.38 and 1.12 , respectively (table 2 ). Current smokers and people with poor self-rated health had higher suicide mortality, after adjustment for other risk factors including alcohol intake status (see online supplementary table S1).

In a stratified analysis by sex, given the same alcohol intake, women seemed to have a higher relative risk of suicide associated with alcohol consumption, compared with men (figure 1). However, $p$ values of the interaction of sex and alcohol intake-related variables with suicide were above 0.05 , due to the small number of suicide deaths. HRs associated with alcohol consumption did not differ between the first half (1985-1996) and the latter half (1997-2008) of the follow-up (see online supplementary figure S1). The HRs of alcohol consumption variables from the sensitivity analysis with reduced covariables to deal with potential overfitting, or violation of the proportional hazards assumption, were generally the same as in the main analysis (see online supplementary table S2).

\section{DISCUSSION}

In our community-based cohort study among the Korean rural elderly, more frequent drinking, a larger amount of alcohol consumption per drinking day and a larger amount of average alcohol consumption were associated with a higher risk of death by suicide. One drinking day increase per week, a $70 \mathrm{~g}$ (5-drink) increase in the average alcohol intake per drinking day, and a $140 \mathrm{~g}$ (10-drink) increase in the average alcohol intake per week were associated with a $17 \%, 38 \%$ and $12 \%$ higher risk of death by suicide, respectively, after adjustment for age, sex, socioeconomic status, behavioural and health-related potential confounders in the Korean elderly.

\section{Relationship to previous research}

Few prospective cohort studies have ever examined the impact of the quantity of usual alcohol consumption on suicide mortality after adjustment for potential confounders. ${ }^{5-7}$ 11-13 17 Among community-based cohort studies, $^{11-13}$ in 43383 Japanese men from a public health centre-based cohort, occasional drinkers had the lowest risk of death by suicide, while non-drinkers and heavy drinkers ( $\geq 414 \mathrm{~g}$ alcohol per week) had 
Table 2 Crude death rates and HRs of suicide death by alcohol consumption-related variables in the Korean elderly

\begin{tabular}{|c|c|c|c|c|c|c|c|c|}
\hline \multirow[b]{2}{*}{ Variables } & \multirow[b]{2}{*}{ Classification } & \multirow[b]{2}{*}{ Person-years } & \multirow{2}{*}{$\begin{array}{l}\text { Number } \\
\text { of suicides }\end{array}$} & \multirow{2}{*}{$\begin{array}{l}\text { Crude suicide } \\
\text { rate }^{*}(95 \% \mathrm{Cl})\end{array}$} & \multicolumn{2}{|c|}{ Unadjusted } & \multicolumn{2}{|c|}{ Multivariable-adjusted } \\
\hline & & & & & p Value & HR $(95 \% \mathrm{Cl})$ & p Value & $\mathrm{HRt}(95 \% \mathrm{Cl})$ \\
\hline \multirow[t]{2}{*}{ Alcohol intake status } & Non-drinker & 61066 & 28 & 46 (32 to 66$)$ & & 1.00 (Reference) & & 1.00 (Reference) \\
\hline & Current drinker & 27310 & 33 & 121 (86 to 170 ) & $<0.001$ & 2.88 (1.74 to 4.77$)$ & 0.097 & $1.70(0.91$ to 3.17$)$ \\
\hline \multirow[t]{4}{*}{ Alcohol intake frequency } & Non-drinker & 61066 & 28 & 46 (32 to 66$)$ & & 1.00 (Reference) & & 1.00 (Reference) \\
\hline & $\begin{array}{l}4 \text { or fewer days a } \\
\text { month }\end{array}$ & 8737 & 6 & 69 (31 to 150$)$ & 0.348 & 1.53 (0.63 to 3.68$)$ & 0.747 & $1.16(0.47$ to 2.91$)$ \\
\hline & 2-6 days a week & 13180 & 15 & 114 (69 to 188$)$ & 0.002 & 2.76 (1.47 to 5.17$)$ & 0.246 & $1.60(0.72$ to 3.52$)$ \\
\hline & Daily & 5393 & 12 & 223 (127 to 389) & $<0.001$ & 5.85 (2.97 to 11.6$)$ & 0.003 & 3.62 (1.56 to 8.43$)$ \\
\hline Alcohol intake frequency & $\begin{array}{l}\text { One drinking day } \\
\text { increase per week }\end{array}$ & 88376 & 61 & 69 (54 to 89) & $<0.001$ & 1.26 (1.16 to 1.38$)$ & 0.006 & $1.17(1.05$ to 1.31$)$ \\
\hline \multirow{4}{*}{$\begin{array}{l}\text { Alcohol intake amount, g } \\
\text { alcohol/drinking day } \\
\text { (drink/drinking day) } \ddagger\end{array}$} & Non-drinker & 61066 & 28 & 46 (32 to 66$)$ & & 1.00 (Reference) & & 1.00 (Reference) \\
\hline & Below $70 \mathrm{~g}$ (5 drinks) & 13796 & 9 & 65 (34 to 124$)$ & 0.260 & $1.54(0.73$ to 3.27$)$ & 0.854 & $1.08(0.48$ to 2.45$)$ \\
\hline & 70-139 (5-9 drinks) & 9670 & 16 & 165 (102 to 269$)$ & $<0.001$ & 3.95 (2.14 to 7.31$)$ & 0.024 & $2.47(1.12$ to 5.41$)$ \\
\hline & $\begin{array}{l}140 \text { or over ( } \geq 10 \\
\text { drinks) }\end{array}$ & 3844 & 8 & 208 (105 to 410$)$ & $<0.001$ & $5.15(2.34$ to 11.3$)$ & 0.028 & 2.84 (1.12 to 7.18$)$ \\
\hline Alcohol intake amount & $\begin{array}{l}\text { 5-drink }(70 \mathrm{~g}) \text { increase } \\
\text { per drinking day }\end{array}$ & 88376 & 61 & 69 (54 to 89) & $<0.001$ & $1.58(1.35$ to 1.85$)$ & 0.002 & 1.38 (1.13 to 1.7$)$ \\
\hline \multirow{5}{*}{$\begin{array}{l}\text { Alcohol intake amount, g } \\
\text { alcohol/week (drink/ } \\
\text { week) } \ddagger\end{array}$} & Non-drinker & 61066 & 28 & 46 (32 to 66$)$ & & 1.00 (Reference) & & 1.00 (Reference) \\
\hline & Below $70 \mathrm{~g}$ (5 drinks) & 10305 & 6 & 58 (27 to 127$)$ & 0.548 & $1.31(0.54$ to 3.16$)$ & 0.976 & $0.99(0.39$ to 2.49$)$ \\
\hline & $\begin{array}{l}70-209 \mathrm{~g}(5-14 \\
\text { drinks) }\end{array}$ & 5605 & 5 & 89 (38 to 209) & 0.098 & $2.24(0.86$ to 5.8$)$ & 0.526 & $1.42(0.48$ to 4.15$)$ \\
\hline & $\begin{array}{l}210-419 \mathrm{~g}(15-29 \\
\text { drinks) }\end{array}$ & 4375 & 8 & 183 (93 to 360$)$ & $<0.001$ & 4.53 (2.06 to 9.95$)$ & 0.022 & $2.99(1.17$ to 7.61$)$ \\
\hline & $\begin{array}{l}420 \mathrm{~g} \text { or over }(\geq 30 \\
\text { drinks) }\end{array}$ & 7025 & 14 & 199 (119 to 334) & $<0.001$ & 4.91 (2.58 to 9.34$)$ & 0.012 & $2.93(1.27$ to 6.78$)$ \\
\hline Alcohol intake amount & $\begin{array}{l}140 \mathrm{~g} \text { (10-drink) } \\
\text { increase per week }\end{array}$ & 88376 & 61 & 69 (54 to 89) & $<0.001$ & $1.16(1.1$ to 1.21$)$ & $<0.001$ & $1.12(1.06$ to 1.19$)$ \\
\hline
\end{tabular}

${ }^{*}$ Death rate per 100000 person-years.

†Adjusted for age at enrolment (continuous variable), sex (men, women), smoking status (current smoker, past smoker, never smoker), body mass index ( $\mathrm{kg} / \mathrm{m}^{2}$; $<18.5,18.5-24.9$,

$\geq 25$ ), hypertension (measured blood pressure $\geq 140 / 90 \mathrm{~mm} \mathrm{Hg}$ or on regular medication; yes, no), self-rated health compared to the same age group (good or fair, poor), marital status

(living with a spouse, not living with a spouse), education (ever, never) and occupation (non-agriculture, agriculture).

$\$ 1$ standard drink as around $14 \mathrm{~g}$ according to the National Institute on Alcohol Abuse and Alcoholism of the USA.

a higher risk; ${ }^{11}$ in another public health centre-based cohort study in 22804 Japanese men (mean age: 60 years), alcohol consumption was linearly associated with suicide death; ${ }^{13}$ in 128934 participants of the Northern California Medical Care Programme in the USA, greater alcohol consumption (especially $\geq 6$ drinks per day) was associated with higher suicide death. ${ }^{12}$ Among occupation-based cohort studies, ${ }^{5-7} 17$ in around 49000
Norwegian conscripts, high alcohol consumption (>250 g/ week) was associated with a non-significantly increased risk of suicide $(\mathrm{HR}=1.7,95 \% \mathrm{CI} 1.0$ to 2.8$)$ compared to moderate consumption (1-100 g/week); ${ }^{17}$ among 89299 physicians and 47654 health professionals in the USA, alcohol consumption was not associated with suicide death; ${ }^{5} 7$ among 1.3 million Korean adults, mostly government and school employees,
Figure 1 HRs of suicide death by alcohol consumption-related variables according to sex. Covariables included in the Cox model were age at enrolment (continuous variable), smoking status (current smoker, past smoker, never smoker), body mass index $\left(\mathrm{kg} / \mathrm{m}^{2} ;<18.5,18.5-24.9, \geq 25\right)$, hypertension (measured blood pressure $\geq 140 / 90 \mathrm{~mm} \mathrm{Hg}$ or on regular medication; yes, no), self-rated health compared to the same age group (good or fair, poor), marital status (living with a spouse, not living with a spouse), education (ever, never) and occupation (non-agriculture, agriculture).
A Current drinker vs. non-drinker

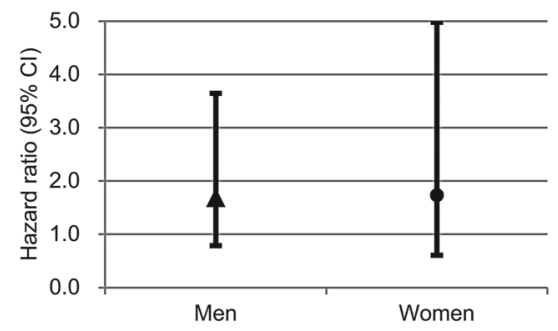

C $\quad 70 \mathrm{~g}$ increase of intake per drinking day

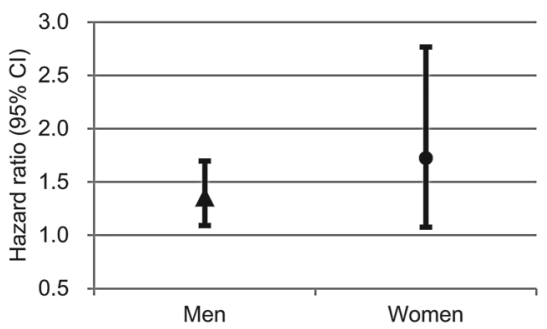

B

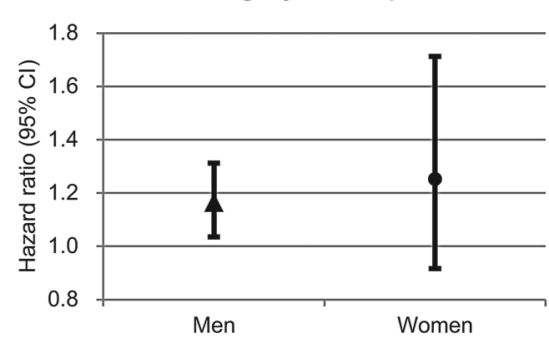

D

$140 \mathrm{~g}$ increase of intake per week

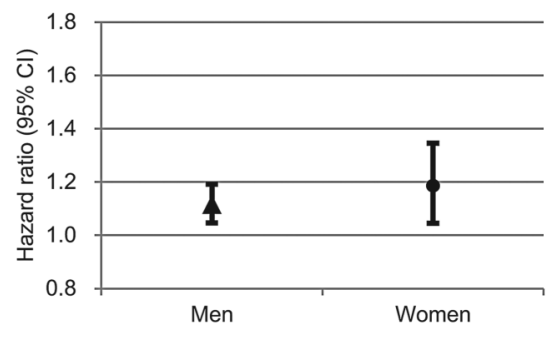


moderate alcohol intake (1-24 g/day), but not high alcohol intake ( $\geq 25 \mathrm{~g} /$ day), was associated with higher suicide mortality and alcohol intake was not linearly associated with suicide death. ${ }^{6}$ Additionally, among nested case-control studies based on prospective cohorts in the USA, the usual amount of alcohol consumption was not associated with suicide death in the community elderly aged 65 years and older, elderly in a retirement community and former college students. ${ }^{8-10}$ Among prospective studies based on a community cohort, three studies examined the associations in the mainly elderly population with a mean age of 60 years or above. ${ }^{9} 1013$

As noted in the previous paragraph, prospective studies have produced inconsistent results on the association between usual alcohol consumption and suicide death. However, results from community-based cohort studies, including the current study, indicated that usual alcohol consumption may be linearly associated with suicide death in the community-dwelling population, at least among current drinkers. ${ }^{11-13}$ Additionally, our study does not support a protective effect of moderate alcohol consumption against suicide mortality in accordance with other, ${ }^{12}{ }^{13}$ but not all, ${ }^{11}$ community-based cohort studies.

As for occupation-based cohort studies, usual alcohol consumption did not generally show a linear dose-response relationship with suicide death. In those studies, participants were mostly healthier, and had a higher socioeconomic status and potentially easier access to healthcare and other resources than the general population. ${ }^{5-7}$ They also had a generally lower alcohol consumption. These factors combined might affect the association between usual alcohol intake and suicide mortality in previous occupation-based cohort studies.

\section{Association in women}

Prospective cohort studies have seldom evaluated the association between usual alcohol consumption and suicide mortality among men and women separately. In this study, estimates of relative risks associated with alcohol consumption variables-a one-drinking-day increase per week, a $70 \mathrm{~g}$ (5-drink) increase of average alcohol intake per drinking day, and a $140 \mathrm{~g}$ (10-drink) increase of average alcohol intake per week-were all higher in women, compared with men. Similar results have been observed in a previous study in Korean adults, showing that women had a higher relative risk associated with moderate alcohol consumption (1-24 g/day), compared with men ( $\mathrm{HR}=1.83,95 \%$ CI 1.09 to 3.07 in women; $\mathrm{HR}=1.20,95 \% \mathrm{CI} 0.93$ to 1.56 in men). ${ }^{6} \mathrm{p}$ Values of the interaction of sex were above 0.05 , partly due to the small number of suicide deaths. However, given the lower body weight as well as the lower threshold of alcohol use for better cardiovascular health in women than in men, our findings may support a lower threshold in women than in men for interventions to prevent suicide death.

\section{Association according to follow-up time}

In this study, relative risks associated with alcohol consumptionrelated continuous variables, unlike depressive symptoms, ${ }^{18}$ did not decrease during the latter half of follow-up (1997-2008), compared with the first half (1985-1996). This finding was concordant with the previous findings in Japanese men that relative risk of death by suicide associated with alcohol consumption did not decrease after exclusion of early follow-up. ${ }^{13}$ This finding suggests that alcohol consumption-related variables may be used as a risk stratification tool for a long-term suicide prevention programme.

\section{Strengths and limitations of the study}

A prospective design and nearly complete long-term follow-up on suicide using national mortality data are one of the strengths of this study. A homogeneous study population with the same ethnicity and culture, who live in the same regional community, is another of its strengths. Yet another strength of our study is that it includes detailed information on alcohol consumption. To the best of our knowledge, only one prospective study examining the association with suicide death collected detailed information on alcohol consumption including drinking frequency, overall average consumption and quantity of alcohol consumed on drinking days. ${ }^{7}$

This study has limitations. First, we observed only 61 suicide deaths, so statistical power may be lacking in some analyses, including the assessment of interaction by sex. However, the number of suicides in persons with high alcohol consumption such as $\geq 30 \mathrm{~g} /$ day was comparable to studies with twice the number of all suicide deaths. ${ }^{5} 712$ Second, our assessment of alcohol consumption was made using a self-reported questionnaire, and it was not validated separately. However, self-report measures of alcohol consumption are known to have reasonable reliability and validity, ${ }^{19}$ and they were assessed prospectively before suicide death. Therefore, potential measurement errors are most likely non-differential with respect to suicide death, and are unlikely to overestimate the risks. Third, depressive symptoms and other psychiatric disorders, strong predictors of suicide death, were not adjusted for. ${ }^{18}$ However, alcohol use status has been suggested to increase the risk of death by suicide, independently of other psychiatric disorders including depression. ${ }^{20}$ Fourth, other potential confounders such as suicidal ideation, detailed information on health burden, social support and socioeconomic status were not included in the analysis. Fifth, our study could not distinguish between never drinkers and ex-drinkers among non-drinkers. Since ex-drinkers tended to have higher suicide mortality in some, ${ }^{11}{ }^{18}$ but not all, ${ }^{13}$ previous studies, the risk of suicide death among current drinkers, compared with never drinkers, may be underestimated in this study. Sixth, suicide death was defined by death certificates. However, any misclassification of suicide, as mentioned earlier, is likely to have been mostly nondifferential with regard to alcohol consumption; thus, potential misclassifications generally would have been unlikely to overestimate the relative risk. Seventh, homogeneity of the participants could also be a limitation of our findings' generalisability. The magnitude of association of risk factors with suicide death may differ by ethnicity, culture, age and level of urbanicity. ${ }^{4} 18$ 21-24 Therefore, some of our findings regarding the Korean rural elderly individuals may have limited generalisability to other ethnic, cultural or age groups, or to urban populations.

\section{CONCLUSION}

Among the Korean rural elderly, the frequency and amount of usual alcohol consumption, per drinking day and per week, had a linear dose-response relationship with suicide death. When consuming alcohol with the same frequency and amount, compared with men, women might have a higher relative risk of suicide. Our findings suggest that there is no protective effect of moderate alcohol consumption on suicide death. Our results also support 'the lower the better' policy of alcohol intake, and a sex-specific alcohol threshold for any suicide prevention strategy implemented. 


\section{What is already known on this subject}

- In a recent systematic review of the prospective studies, the magnitude of the association between alcohol use disorder and suicide death was moderate (pooled risk ratio $=1.74$, $95 \% \mathrm{Cl} 1.26$ to 2.21 ).

- Evidence that greater usual alcohol consumption is associated with higher suicide death in the prospective studies among the general population is inconclusive.

\section{What this study adds}

- The greater frequency and amount of usual alcohol consumption was linearly associated with higher suicide death, and there was no protective effect of moderate alcohol consumption against suicide death in the elderly persons in a rural community.

- When consuming alcohol with the same frequency and amount as men, women might have a higher relative risk of suicide.

\author{
Author affiliations \\ ${ }^{1}$ Department of Preventive Medicine and Public Health, Catholic Kwandong \\ University College of Medicine, Gangneung, Republic of Korea \\ ${ }^{2}$ Institute for Clinical and Translational Research, Catholic Kwandong University \\ College of Medicine, Gangneung, Republic of Korea \\ ${ }^{3}$ Department of Public Health, Yonsei University Graduate School, Seoul, Republic of \\ Korea \\ ${ }^{4}$ Department of Epidemiology and Health Promotion, Graduate School of Public \\ Health, Yonsei University, Seoul, Republic of Korea \\ ${ }^{5}$ Department of Biomedical Laboratory Science, Eulji University College of Health \\ Science, Sungnam, Republic of Korea \\ ${ }^{6}$ Department of Nursing, Sangmyung University, Cheonan, Republic of Korea \\ ${ }^{7}$ Department of Preventive Medicine, Yonsei University College of Medicine, Seoul, \\ Republic of Korea
}

Acknowledgements The authors truly thank the staff of the Korean National Statistical Office for the provision of the mortality data used herein.

Contributors SWY and HO conceived the study concept and design, and acquired the data. SWY and MJ analysed the data and wrote the first draft. SWY, MJ, HK, EL, $\mathrm{KOL}$ and $\mathrm{HO}$ interpreted the data. SWY, JWS and HO contributed to a critical revision of the manuscript. All authors have read and approved the final submitted version of the manuscript. SWY is the study guarantor.

Funding The original survey was supported by a Korea Science and Engineering Foundation grant (KOSEF: R-01-1993-000-00073-0).

Competing interests None declared.

Patient consent Obtained.

Ethics approval Institutional Review Board of Yonsei University.

Provenance and peer review Not commissioned; externally peer reviewed.
Open Access This is an Open Access article distributed in accordance with the Creative Commons Attribution Non Commercial (CC BY-NC 4.0) license, which permits others to distribute, remix, adapt, build upon this work non-commercially, and license their derivative works on different terms, provided the original work is properly cited and the use is non-commercial. See: http://creativecommons.org/ licenses/by-nc/4.0/

\section{REFERENCES}

1 Heron M. Deaths: leading causes for 2011. Natl Vital Stat Rep 2015;64:1-96.

2 World Health Organization. Preventing suicide: a global imperative. Geneva: World Health Organization, 2014.

3 Yoshimasu K, Kiyohara C, Miyashita K, Stress Research Group of the Japanese Society for Hygiene. Suicidal risk factors and completed suicide: meta-analyses based on psychological autopsy studies. Environ Health Prev Med 2008;13:243-56.

4 Kaplan MS, Huguet N, McFarland BH, et al. Use of alcohol before suicide in the United States. Ann Epidemiol 2014;24:588-92.e1-2.

5 Gaziano JM, Gaziano TA, Glynn RJ, et al. Light-to-moderate alcohol consumption and mortality in the Physicians' Health Study enrollment cohort. J Am Coll Cardiol 2000;35:96-105.

6 Jee SH, Kivimaki M, Kang HC, et al. Cardiovascular disease risk factors in relation to suicide mortality in Asia: prospective cohort study of over one million Korean men and women. Eur Heart I 2011;32:2773-80.

7 Mukamal KJ, Kawachi I, Miller M, et al. Drinking frequency and quantity and risk of suicide among men. Soc Psychiatry Psychiatr Epidemiol 2007;42:153-60.

8 Paffenbarger RS Jr, King SH, Wing AL. Chronic disease in former college students. IX. Characteristics in youth that predispose to suicide and accidental death in later life. Am J Public Health Nations Health 1969;59:900-8.

9 Ross RK, Bernstein L, Trent L, et al. A prospective study of risk factors for traumatic deaths in a retirement community. Prev Med 1990;19:323-34.

10 Turvey $\mathrm{CL}$, Conwell Y, Jones MP, et al. Risk factors for late-life suicide: a prospective, community-based study. Am J Geriatr Psychiatry 2002;10:398-406.

11 Akechi T, Iwasaki M, Uchitomi Y, et al. Alcohol consumption and suicide among middle-aged men in Japan. Br J Psychiatry 2006;188:231-6.

12 Klatsky AL, Armstrong MA. Alcohol use, other traits, and risk of unnatural death: a prospective study. Alcohol Clin Exp Res 1993;17:1156-62.

13 Nakaya N, Kikuchi N, Shimazu T, et al. Alcohol consumption and suicide mortality among Japanese men: the Ohsaki Study. Alcohol 2007;41:503-10.

14 Yi SW, Odongua N, Nam CM, et al. Body mass index and stroke mortality by smoking and age at menopause among Korean postmenopausal women. Stroke 2009; 40:3428-35.

15 Yi SW, Sull JW, Linton JA, et al. Alcohol consumption and digestive cancer mortality in Koreans: the Kangwha Cohort Study. J Epidemiol 2010;20:204-11.

16 National Institute on Alcohol Abuse and Alcoholism. Helping patients who drink too much: a clinician's guide. Updated 2005 Edition. Bethesda, MD: National Institute on Alcohol Abuse and Alcoholism, 2007.

17 Andreasson S, Romelsjo A, Allebeck P. Alcohol, social factors and mortality among young men. Br J Addict 1991;86:877-87.

18 Yi SW, Hong JS. Depressive symptoms and other risk factors predicting suicide in middle-aged men: a prospective cohort study among Korean Vietnam War veterans. PeerJ 2015;3:e1071.

19 Del Boca FK, Darkes J. The validity of self-reports of alcohol consumption: state of the science and challenges for research. Addiction 2003;98(Suppl 2):1-12.

20 Flensborg-Madsen T, Knop J, Mortensen EL, et al. Alcohol use disorders increase the risk of completed suicide-irrespective of other psychiatric disorders. A longitudinal cohort study. Psychiatry Res 2009;167:123-30.

21 Zhang J, Conwell Y, Zhou L, et al. Culture, risk factors and suicide in rural China: a psychological autopsy case control study. Acta Psychiatr Scand 2004;110:430-7.

22 Goldston DB, Molock SD, Whitbeck LB, et al. Cultural considerations in adolescent suicide prevention and psychosocial treatment. Am Psychol 2008;63:14-31.

23 Milner $\mathrm{A}$, Hjelmeland $\mathrm{H}$, Arensman $\mathrm{E}$, et al. Social-environmental factors and suicide mortality. Sociology Mind 2013;3:137-48.

24 Qin P. Suicide risk in relation to level of urbanicity—a population-based linkage study. Int J Epidemiol 2005;34:846-52. 